\title{
How to be an Effective Athletic Training Preceptor: A Literature Review
}

Daniella C. Eiroa DAT, LAT, ATC

Florida International University, deiro001@fiu.edu

Jeff G. Konin PhD, ATC, PT, FACSM, FNATA

Florida International University, jkonin@fiu.edu

Follow this and additional works at: https://nsuworks.nova.edu/ijahsp

Part of the Educational Methods Commons, and the Medicine and Health Sciences Commons

\section{Recommended Citation}

Eiroa DC, Konin JG. How to be an Effective Athletic Training Preceptor: A Literature Review. The Internet Journal of Allied Health Sciences and Practice. 2021 Jan 01;19(1), Article 4.

This Literature Review is brought to you for free and open access by the College of Health Care Sciences at NSUWorks. It has been accepted for inclusion in Internet Journal of Allied Health Sciences and Practice by an authorized editor of NSUWorks. For more information, please contact nsuworks@nova.edu. 


\title{
How to be an Effective Athletic Training Preceptor: A Literature Review
}

\begin{abstract}
Background: The purpose of this literature review is to identify successful characteristics that have been found to be associated with effective precepting for the athletic training profession. Athletic training programs use preceptors as their main source of hands-on experience for athletic training students. Thus, a clinical preceptor who possesses these characteristics are better positioned to impact the success of a student's clinical experience and overall growth. Purpose: To identify successful characteristics for athletic training preceptors. Methods: The findings of the literature review were achieved by the selection of articles that specifically pertained to athletic training and to other health care professions alike that investigated the most effective characteristics associated with clinical precepting. Conclusion/ Recommendations: Athletic trainers currently serving as a preceptor should have a set standard on how to educate a student under their professional guidance. Not only is this a common theme discussed in many articles specific to the athletic training profession, but the strategies and characteristics of precepting are equally as important to other health care professions as well.
\end{abstract}

\section{Author Bio(s)}

Daniella Eiroa DAT, LAT, ATC was a student of the Doctor of Athletic Training Program at Florida International University.

Jeff G. Konin, PhD, ATC, PT, FACSM, FNATA is a Clinical Professor and the Director of the Doctor of Athletic Training Program at Florida International University.

\section{Acknowledgements}

Writing this literature review has been one of the most significant academic challenges that I have ever had to face. Without the support, patience and guidance I received from my mentor Dr. Wendy Hebert and classmate Shaniece Jackson, this research would not have been possible. Once again thank you for your efforts and continued support. I could not have done it without you. 


\title{
IIJAHSP \\ The Internet Joumnal of Allied Health Sciences and Practice \\ Dedicated to allied health professional practice and education
}

Vol. 19 No. 1 ISSN 1540-580X

\section{How to be an Effective Athletic Training Preceptor: A Literature Review}

\author{
Daniella C. Eiroa \\ Jeff G. Konin \\ Florida International University \\ United States
}

\begin{abstract}
Background: The purpose of this literature review is to identify successful characteristics that have been found to be associated with effective precepting for the athletic training profession. Athletic training programs use preceptors as their main source of hands-on experience for athletic training students. Thus, a clinical preceptor who possesses these characteristics are better positioned to impact the success of a student's clinical experience and overall growth. Purpose: To identify successful characteristics for athletic training preceptors. Methods: The findings of the literature review were achieved by the selection of articles that specifically pertained to athletic training and to other health care professions alike that investigated the most effective characteristics associated with clinical precepting. Conclusion/ Recommendations: Athletic trainers currently serving as a preceptor should have a set standard on how to educate a student under their professional guidance. Not only is this a common theme discussed in many articles specific to the athletic training profession, but the strategies and characteristics of precepting are equally as important to other health care professions as well.
\end{abstract}

Keywords: preceptor, effective precepting, athletic training

(C) The Internet Journal of Allied health Sciences and Practice, 2021 


\section{INTRODUCTION}

Clinical preceptors are identified to be a crucial component of the learning process across the medical profession. ${ }^{1}$ Preceptors play a primary role in the learning process of not only athletic training students but in other allied health care professions as well. A preceptor is expected to set the best example possible to enhance and provide the current knowledge possible for a successful transition from being a student to a practitioner. ${ }^{1}$ It is during these clinical environment experiences where students start to develop their style, and often times, model their practice following what they have learned from a preceptor. ${ }^{2}$ Previously, the process of selecting a preceptor for an athletic training student was based on the level of experience one had in the profession, with the average being 2 years of experience and a bachelor's degree minimum. ${ }^{3} \mathrm{~A}$ recurring theme in the current literature is evident in educational preceptor programs of varying disciplines. For example, The American Society of Health System Commission on Credentialing (ASHSCC) and the Commission on Accreditation of Athletic Training Education (CAATE) have both recommended implementing a preceptor development strategy. With the recent advancement and growth of the athletic training profession, the criteria for selecting a preceptor has appropriately changed. Since September 2016, preceptors are now mandated to complete an annual course on how to be an "effective preceptor." ${ }^{4}$ The specifics of the formal preceptor training are individualized by each accredited program and are usually designed to complement the culture and philosophy of the program. The material included can vary from "how to evaluate a student's skills" to "providing a student with critical feedback." As Altmann notes, the nursing and athletic training professions have similar selection criteria for preceptors whereby the main factors considered for precepting are years of experience, level of education, attitude, communication skills, and the ability to influence the critical thinking of a student. ${ }^{3}$

Meyer's work in 2002 revealed that $57 \%$ of respondents surveyed reported that they wanted to learn more about becoming a preceptor. ${ }^{5}$ There are seven qualities highlighted in the current literature that outlines the qualities of an effective preceptor: legal and ethical behavior, communication skills, interpersonal relationships, instructional skills, supervisory and administrative skills, evaluation of performance, and clinical skills and knowledge. It is suggested that the ideal preceptor possesses all of these qualities and potentially more. The reason why these factors are highly sought is because the more well-rounded the preceptor is, the greater the likelihood that the academic program will possess better learning outcomes for the students. ${ }^{3}$

\section{REVIEW OF THE LITERATURE \\ Legal and Ethical Behavior:}

Health care practitioners should always act within the boundaries of sound legal and ethical behavior. ${ }^{6}$ Athletic trainers should follow the ethical and legal behavior guidelines recommended by the NATA code of conduct and the appropriate state's governing laws. 6,7 Though the rules of legal and ethical behavior are generally well known, it is possible for codes of conduct and legal guidelines to change when necessary. As students, all future health care professionals are taught about liability and ethics. However, after graduation, reviewing current guidelines is probably not high on any health care professionals' list of things to do. In many cases, athletic trainers are taught these rules and regulations when they are in school, meaning they are concepts not fresh in their minds. One recommended strategy to help both the preceptor and the athletic training student practice legal and ethical behavior is to include this topic in their initial meeting, which usually includes rules and regulations to follow in the athletic training clinic. This can help practicing clinicians stay up to date with the current laws and NATA code of conduct and the student can foster the habit of reviewing the regulations from time to time. Another recommendation of implementation could be role playing. The preceptor can come up with real life situations to role play with their athletic training student. This can help stimulate conversation and help with critical thinking skills. For example, the preceptor may go over the law with the student and create a scenario that may be considered negligent. The scenario may be that an athlete has suffered a concussion during a game, but the coach is threatening the athletic trainer to put the player back in the game since they are the best player on the team, and they need to win this game. What should the athletic trainer do to not commit an act of negligence? Then the second scenario to be explored would be if the athlete trainer did allow the concussed athlete back into the game to please the coach. This scenario will help stimulate both sides of the conversation and will help the student critically think about what is right and wrong.

\section{Communication Skills:}

Athletic trainers must communicate with countless individuals every day. When the role is that of a mentor or educator, it may be difficult because the level of communication is different for each occasion. There are many ways a preceptor must communicate with their students. It may be in the form of writing an email, completing an evaluation, or via verbal or body language mannerisms. ${ }^{8}$ The preceptor should always create a non-judgmental and safe environment that encourages open communication.2,5,6 The student should be able to feel comfortable approaching the preceptor with any issue at hand without feeling afraid or uncomfortable. ${ }^{9} \mathrm{It}$ is highly recommended to demonstrate good listening skills when communicating with students as it tends to foster more positive outcomes. ${ }^{6}$ If the preceptor feels that they need to improve their communication skills, reaching out to the student and asking for their feedback about on it can potentially help improve the situation.

(C) The Internet Journal of Allied health Sciences and Practice, 2021 


\section{Interpersonal Relationships:}

Athletic trainers are empirically known for the passion and interest that they have in their jobs and it should translate to teaching. When engaging with students, the interactions and intentions of the preceptor should be genuine. ${ }^{2}$ The preceptor should show desire to want to help improve the quality of learning the student is receiving each day. One way that students learn is through interactions. In the nursing profession, Singer demonstrated that a preceptor should be a nurturer to help the student feel comfortable, establish relationships, and aid in the learning process. ${ }^{1}$

A recommended method to possibly develop an interpersonal relationship is by sharing stories. This will help simulate conversation, helping the students understand that they are not the only ones who have made mistakes while still learning. When sharing a story, it helps the athletic training student connect to the preceptor better by finding a common ground. ${ }^{10}$ For example, the preceptor may share a story of embracing a mistake they committed while learning in their clinical rotations. This may help create a safe and judgement free zone that will help the student feel comfortable.

\section{Instructional and Supervisory Skills:}

Instructional and supervisory skills are some of the most crucial components for an athletic trainer to possess. There needs to be a strong grasp of the learning style of the students in their clinical rotation. ${ }^{2,5,7}$ Once the preceptor has mastered each students' learning style, then they should challenge the students' thought process. Athletic training students should be allowed to have their freedom while still being watched to help develop their clinical skills on a live patient. Dr. William Osler said "by what may be called the natural method of teaching, the student begins with the patient, continues with the patient, and ends their studies with the patient, using books and lectures as a tool, as a means to an end."12(parab) This hallmark and profound statement published nearly a century ago has equally as much merit in today's clinical education environment.

The preceptor should foster a judgement free environment and should provide positive and constructive feedback whenever appropriate. ${ }^{1,5,7} \mathrm{As}$ a recommendation to improve the implementation of instructional skills, the preceptor should allow the student to have opportunities in the clinic to exercise their skill set under the guidance of the certified athletic trainer. Another recommendation is to create simulated scenarios. The athletic trainer can cover anything from a medical emergency to a conversation with a coach with a simulation. This will help the student have a near real life experience and help develop skills that may not be necessarily taught in the classroom.

In addition to the preceptor having the ability to show their knowledge, it is important for the preceptor to be interested in not only advancing their clinical knowledge but to want to advance their teaching skills. There are many techniques the preceptor can add to their daily teaching methods that will simulate the ability to critically think and develop the clinical skills of the student. ${ }^{12}$ One suggested technique for the preceptor to use is called the "One-minute preceptor method." This entails the preceptor creating a safe and judgement free conversation with the students about a topic that will make the students have to critically think and come up with a well-rounded answer. ${ }^{12}$

\section{Administrative Skills:}

The duties of athletic training are not limited to just clinical care and coverage. It is an extensive line of work including administrative tasks, leaving the athletic trainer strained. ${ }^{12}$ Athletic trainers are known for their ability to multitask multiple aspects of their jobs, leading to being proficient in delegation and having an extremely good grasp of time management. Preceptors should allow the student to perform some of those other tasks under their direct supervision, such as booking a medical appointment for a student athlete or helping create a new organizational spreadsheet. ${ }^{12}$ Administrative skills may be difficult for students as a result of the challenges academic programs face to simulate scenarios given the often-changing requirements from one institution to another.

An example a preceptor can use to simulate this learning process is for the athletic training student to be allowed to help create an agenda for a staff meeting and come up with talking points. The preceptor may throw the student a curve ball and give them a "problem" to solve. It could be a scenario where there is an issue with the budget, for example. They can brainstorm to figure out how money can be allocated differently to help fund the supplies needed.

\section{Evaluation of Performance:}

Unfortunately, preceptors tend to not get immediate feedback about their performance throughout the semester. On most occasions, feedback is not received until the student has completed the clinical rotation. Altmann has reported that there is little attention dedicated to the evaluation of the preceptor. ${ }^{3}$ How can a preceptor improve without feedback? The preceptor evaluation is a critical component to the growth of the preceptor because it is the evaluation of their experience and effectiveness and can reveal the strengths and weaknesses of the preceptor. Furthermore, if based on a one-time experience with a student, feedback

(C) The Internet Journal of Allied health Sciences and Practice, 2021 
will not be anonymous and could merely be situation specific. On the other hand, if feedback is provided after multiple supervisory experiences with many students, while better serving to protect the student's anonymity, the actual feedback may not be timely and as valuable. While it is fair to provide specific examples of feedback, doing so may also make for an uncomfortable situation between the preceptor and the student.

Most students are uncomfortable or fearful to give honest feedback to a person who controls much of their education as it relates to their grade and a potential future professional reference.5,6 Regardless, preceptors still need the feedback to reflect and understand their areas of strengths and weakness. In these instances, faculty and students play an important role in the professional development of a preceptor. One way the student might feel comfortable in providing crucial feedback may be if the student has a good relationship with the preceptor. A suggested way for the preceptor to gain instant feedback is for the preceptor to create an assessment tool for themselves and provide it to their students throughout the semester. That way both the student and the preceptor are both being evaluated and there can be an open line of communication.

On the other hand, the preceptor is expected to also give a student an overall evaluation at the culmination of the clinical rotation. In 2017, Hankemeier et al conducted a study which showed that $57 \%$ of respondents agreed that the ability of a preceptor to provide constructive feedback to the student was considered one of the most important components of the clinical educational experience. ${ }^{11}$ Some preceptors feel that they can educate the student but cannot provide a proper evaluation of the performance of the student. ${ }^{11}$ The evaluation of a student is an important component of the educational process for the student's development. Unless the program has a set standard for the feedback given by the preceptor, there really is no proper guideline. A recommendation made by the Hankemeier study is for the preceptor to simulate a scenario where the student may have to activate the emergency action plan. ${ }^{11}$ This will give the preceptor a set rubric with which to evaluate the student. At the end of the activity, the preceptor can discuss the missed areas and the areas of a good performance.

\section{Clinical Skills and Knowledge:}

The preceptor shows their knowledge through the application of treatments in practice. It is crucial that the preceptor uses evidencebased practice (EBP) approaches. ${ }^{8}$ The preceptor should always be able to provide a sound explanation as to why the treatment being applied is the best treatment available and then proceed to properly conduct the treatment. ${ }^{2}$ One way for a student to develop the good habit of using EBP is for the preceptor to challenge the student to conduct their own research on the web to find appropriate, peer-reviewed studies for their clinical decisions and openly discuss them in the clinic.

\section{CONCLUSIONS:}

This review of the literature suggests common findings for athletic training preceptors as it relates to educating students in the clinical setting. The common themes identified appear to pertain to all allied health preceptors and are especially applicable to the athletic training profession. The most distinguishing characteristics for an athletic training preceptor to have are the following: legal and ethical behavior, communication skills, interpersonal relationships, instructional skills, supervisory and administrative skills, evaluation of performance, and clinical skills and knowledge. As the profession of athletic training continues to evolve, future research may identify additional characteristics of effective clinical teaching.

\section{References:}

1. Singer C. A preceptor training program model for the hemodialysis setting. Nephrol Nurs J. 2006;33(6):623-630.

2. Weidner T, Henning J. Being an effective athletic training clinical instructor. Athl Ther Today. 2002;7(5):6-11.

3. Altmann TK. Preceptor selection, orientation, and evaluation in baccalaureate nursing education. Int J Nurs Educ Scholarsh. 2006;3:Article 1. doi: 10.2202/1548-923X.1014. Epub 2006 Jan 12. PMID: 16646936.

4. CAATE. Net B. Standards. Accessed January 25, 2020. https://caate.net/pp-standards/.

5. Platt Meyer LS. Leadership characteristics as significant predictors of clinical-teaching effectiveness. Athl Ther Today. 2002;7(4):34-39.

6. Weidner TG, Henning JM. Importance and applicability of approved clinical instructor standards and criteria to certified athletic trainers in different clinical education settings. J Athl Train. 2005;40(4):326-332.

7. Levy LS, Sexton P, Willeford KS, et al. Clinical instructor characteristics, behaviors and skills in allied health care settings: a literature review. Athl Train Educ J. 2009;4(1):8-13.

8. Weidner TG, Henning JM. Historical perspective of athletic training clinical education. J Athl Train. 2002;37(suppl 4):S222.

9. Nottingham S, Barrett JL, Mazerolle SM, Eason CM. Examining the role mentorship plays in the development of athletic training preceptors. Athl Train Educ J. 2016;11(3):127-137.

(C) The Internet Journal of Allied health Sciences and Practice, 2021 
10. Nottingham S. Preceptors' Perceptions of the Preparation and Qualifications for the Preceptor Role. Athl. Train. Educ. J. 2015;10(4). https://doi.org/10.4085/1004302

11. Bryan, CS. Sir William Osler (1849-1919). Reprinted from www. antimicrobe.org, n.d.

12. Hankemeier DA, Kirby JL, Walker SE, Thrasher AB. 2017. Athletic training preceptors' perceived learning needs regarding preceptor development. Athl Train Educ J. 2017;12(1):3945. 